\title{
APPROACH TO ALGORITHMIC CONTROL OF OPTICAL NETWORK NODES IN MONITORING TASKS
}

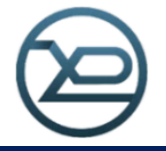

\author{
L.S. DEREVIANKO, L.O. TOKAR, Y.O. KRASNOZHENIUK
}

Kharkiv National University of Radio Electronics

\begin{abstract}
The necessity of monitoring passive optical networks (PONs) is considered. It is shown that the monitoring task is important for preventing network downtime and faults, maintaining fault tolerance and security of information transmission in order to provide the customer service with operational and reliable data on the current and forecasted state of a fiber-optic communication line. The PON architecture is considered, and it is shown that for high-quality network monitoring it is necessary to implement periodic polling of all available OLTs and tracking important indicators: detecting ONUs on OLTs that are not included in the ONU database, or have been registered simultaneously on two OLTs. Algorithms have been developed that allow processing and outputting OLT data structured according to PON specifics: an algorithm for adding a new OLT and obtaining information about ONUs, an algorithm for displaying information about ONUs in real time, and an algorithm for displaying information about client devices in real time. It is shown that in the process of monitoring a PON, an important role is played by data obtained in real time, i.e. on demand. The choice of SNMP protocol for management has been substantiated. The features of the SNMP protocol are analyzed.
\end{abstract}

Анотація - Розроблено алгоритми, які дозволяють обробляти та виводити дані Optical Line Terminal, щз структуровані під специфіку PON: алгоритм додавання нового OLT й отримання інформацї про Optical Network Units, алгоритм відображення інформації про ONU в режимі реального часу та алгоритм відображення інформації про клієнтські пристрої в режимі реального часу. Показано фрагмент створення бази даних на прикладі OLT, що є основним об' єктом системи.

\begin{abstract}
Аннотация - Разработаны алгоритмы, позволяющце обрабатывать и вьводить данные Optical Line Terminal, структурированные под специифику PON: алгоритм добавления нового OLT и получения информации об Optical Network Units, aлгоритм отображения информации об ONU в режиме реального времени и алгоритм отображения информации о клиентских устройствах в режиме реального времени. Показан фрагмент базы данных на примере OLT, являющимся основным объектом системьл.
\end{abstract}

\section{Introduction}

Network management is an important function, therefore, it is often separated from other functions of control systems and implemented by special means. Constant monitoring of a network is necessary to maintain it in working state. The first stage of control is monitoring. At this stage, the procedure for collecting primary data on network operation is performed. The tasks of monitoring are solved by software and hardware meters, testers, network analyzers, built-in monitoring tools of communication devices as well as control system agents.

The technology of passive optical networks (PONs) is an economical way of providing broadband information transfer and is based on a tree-like fiber-cable architecture with passive optical splitters on nodes [1]. The PON architecture has the necessary efficiency of increasing network nodes and bandwidth depending on the current and future 
needs of subscribers. The stage of monitoring the state of the network is crucial, which will reduce the time spent on troubleshooting in the network, and thus ensure its continuous and high-quality operation.

The urgency of this issue is conditioned by the need to prevent downtime and faults in the network, maintain the fault tolerance and security of information transmission over the network, and provide the customer service with timely and reliable data on the current and predicted state of the fiber-optic communication line.

\section{Review of network diagnostic and monitoring methods}

The existing methodologies for network diagnostics and monitoring are not sufficiently precise and too abstract, implying that all the work on the analysis and adjustment procedure is on the service personnel. For monitoring both large networks and simply large-scale corporate local resources, there is an urgent task in universal automated search and troubleshooting algorithms, which reduces the system administrators' labor costs for servicing, identifying failures and troubleshooting.

In [2], hybrid neural networks for monitoring and predicting the state of networks are considered. Such monitoring systems are successfully used in many segments of the network and provide the desired results with low computational costs. However, in most cases, the areas of application of hybrid neural networks as elements of monitoring, remote control and administration systems are severely limited.

In [3], the principles of constructing sensor passive optical networks that implement the concept of a single field of fiber-optic sensors based on hybrid wave and time multiplexing were analyzed. This approach allows to create spatially separated and multidimensional sensor networks based on them, used in structural monitoring systems and solving other problems.

The authors of [4] propose to use an optical reflectometer operating in the visible region of the spectrum to monitor the state of subscriber sites. The considered solution will allow to sharply increase the frequency of the probing signals, to increase the number of signal accumulations during the measurement.

The paper [5] presents an algorithm for automatic diagnostics and troubleshooting, which analyzes the hosted network, decides or suggests alternative options in case if it is impossible to resolve the emerged problem. The given algorithm was developed in VBScript or JavaScript languages, which are simple and convenient for this purpose, and there is also a ability to use written scripts in terminal programs.

\section{Work-related analysis and problem statement}

The central idea of the PON architecture is to use the main Optical Line Terminal (OLT), which contains both Ethernet ports for connecting uplink channels and optical output ports for transmitting information to a set of Optical Network Terminals (ONTs), which are called Optical Network Units (ONUs), and receiving information from them. The number of ONTs, which are connected to one OLT, depends on the power and maxi- 
mum speed of the receiving and transmitting equipment [6]. The main elements of the PON architecture are shown in Fig. 1.

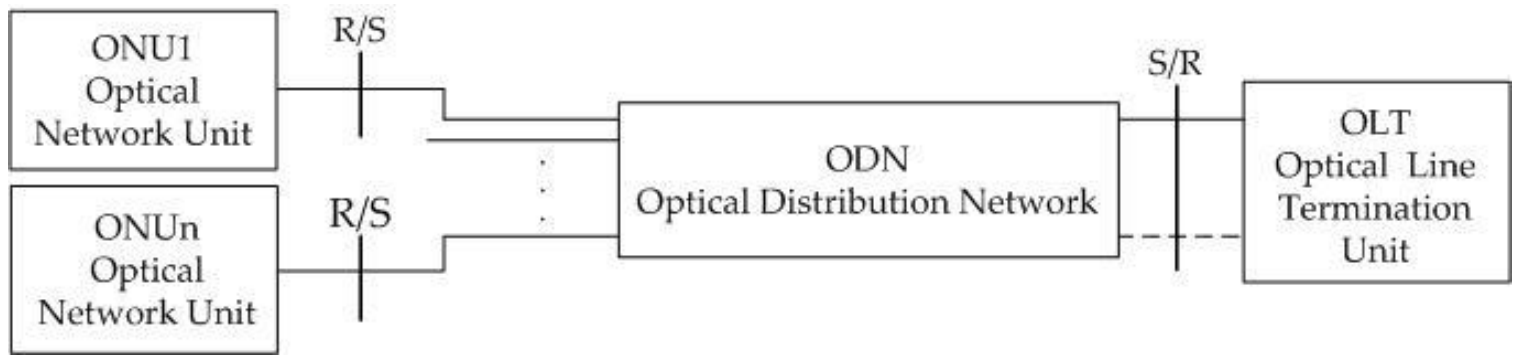

Fig. 1. Basic PON architecture elements

The direct flow at the optical signal level is broadcast. Each ONT subscriber node reads address fields and extracts from this shared flow only the part of information intended for it. All ONTs transmit in the return flow at the same wavelength and use the Time Division Multiple Access (TDMA) concept. To eliminate the intersection of signals from different ONTs, each of them has its own individual schedule for data transfer, taking into account the delay correction associated with the removal of this ONT from the OLT.

Information on the number and state of ONUs during the process of adding a new OLT should include: a list of SNMP interfaces connected to ONUs in the PON interface, numbers of the PON interfaces, state of the uplink port of the ONU and its traffic, state of other ONU ports.

Thus, for PON documenting and the convenience of monitoring its efficient operation, algorithms are needed that allow real-time processing and outputting OLT data, which are structured to the specifics of PON and this OLT model.

Below are the algorithms developed by the authors to assess the state of the network. The proposed algorithms are the basis for developing a control system and monitoring a passive optical network.

\section{Algorithm for adding new OLT and getting information about ONUs}

For monitoring, a periodic poling of all existing OLTs and tracking of important indicators are carried out: detection of ONUs on the OLT, which are not added into the ONU database, or registered simultaneously on two OLTs.

To develop an algorithm for adding a new OLT and obtaining information about the ONUs, it is proposed to use SNMP management. The protocol allows unified management of equipment of different manufacturers, which works with different operating systems and at different levels of the OSI model. Due to its simplicity and efficiency, this protocol is used to manage almost any type of equipment and software of computer networks [7].

The architectural model of the Simple Network Management Protocol (SNMP) is a collection of network management stations and managed network elements. At the net- 
work management stations, programs are executed that provide monitoring and control of network elements - the so-called managers. A software agent is implemented in the network agent. An agent in the SNMP protocol is a processing element that provides managers with access to the values of Management Information Base (MIB) variables hosted on management stations of the network, and thus it enables them to implement device management and control functions.

The following elements are standardized in management systems based on the SNMP protocol: agent-manager interaction protocol, MIB model description language and SNMP messages (ASN.1 is an abstract syntax notation language [8]). In addition, several specific MIB models (MIB-I, MIB-II, RMON, RMON 2) are standardized, the names of objects of which are registered in the tree of ISO standards.

SNMP is a request-response protocol, that is, for each request received from the manager the agent must transmit a response. SNMP uses UDP datagram transport protocol, which does not provide reliable message delivery. The block diagram for adding a new OLT and obtaining information about the ONUs is shown in Fig. 2.

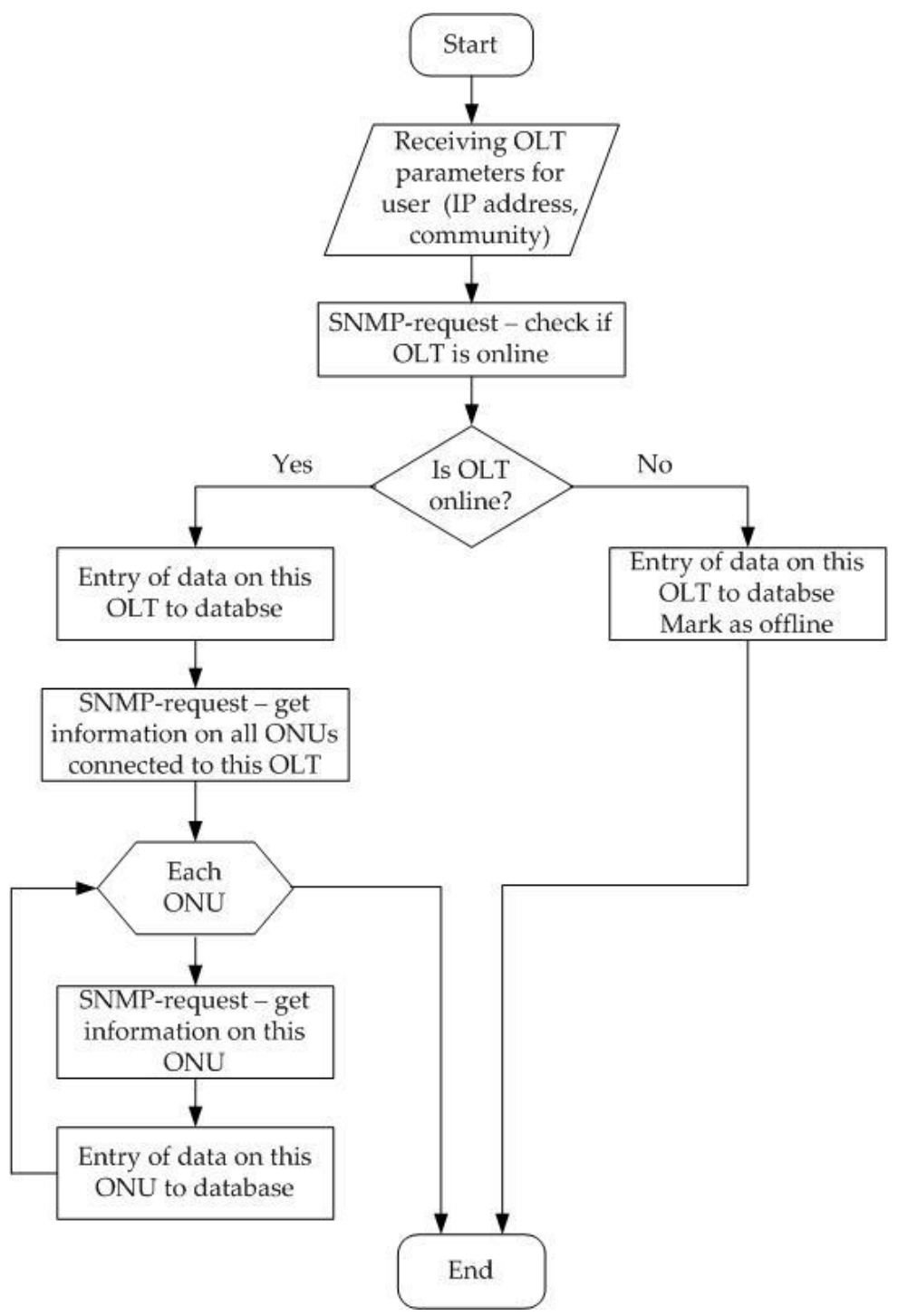

Fig. 2. The block diagram for adding a new OLT and receiving information about the ONU 
At the first stage, important data about the new OLT is received from the user: IP addresses of OLT, locations, community name, coordinates.

At the second stage, an SNMP request is sent to check whether the OLT is online and responding to the request. After this request, all information about this OLT is recorded in the database, but if the OLT is offline, then the flag "offline" is added. If the OLT is online, an SNMP request is sent to get all the information on the ONUs that belong to this OLT.

The third stage allows to create an array of ONUs, in the cycle of which a check is performed for each element in the array (for each ONU). After that, an SNMP request is sent to receive all the information about a specific ONU and the ONU is recorded to the database.

\section{Algorithm for displaying information about $\mathrm{ONU}$ in real time}

In the process of monitoring the network, an important role belongs to the data obtained in real time, i.e. on-demand. Fig. 3 shows a block diagram for obtaining information about a specific ONU. The presented algorithm displays information about the signal levels of the OLT-ONU and ONU-OLT as well as data on the distance of the OLT-ONU.

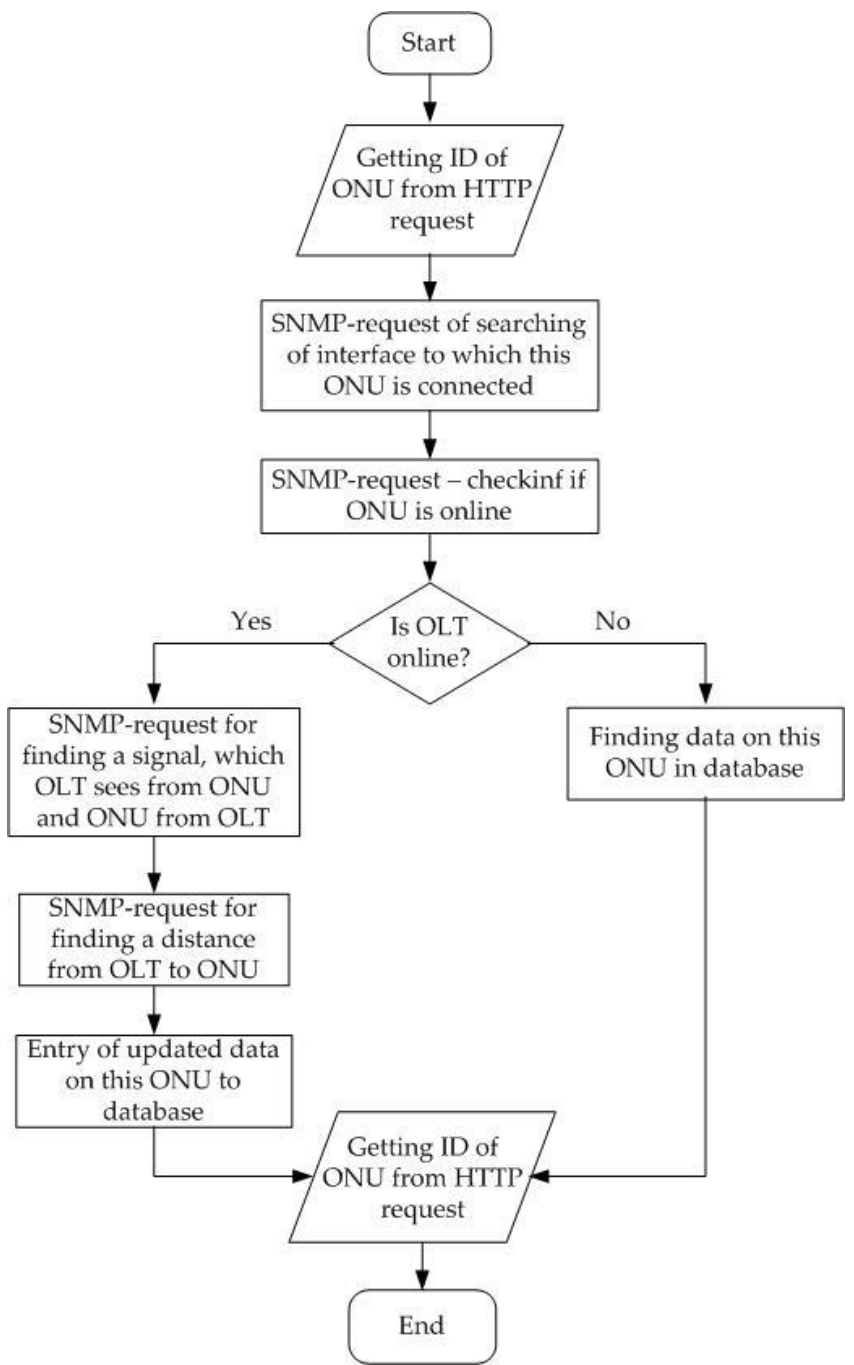

Fig. 3. The block diagram of the algorithm for displaying information about the ONU in real time 
At the first stage, a unique ONU identifier should be obtained from the HTML request. After that information about this ONU can be found by the given ID in the database and the OLT, which this ONU belongs to.

At the second stage, having the IP address of the OLT, an SNMP request is made to find the OLT interface to which this ONU is connected.

At the third stage, an SNMP request is made for a specific OLT interface and to check whether the ONU is online. If the ONU is offline, then the data about this ONU is displayed in the database and is shown to the user with a notification that the ONU is offline. If the ONU is online, an SNMP request is made for the signal level from the OLT to the ONU and from the ONU to the OLT, and then the next SNMP request is made to find the distance from the OLT to the ONU. If there is a change in the data, the new data is recorded into the database and displayed to the user.

\section{Algorithm for displaying information about client devices in real time}

Fig. 4 shows the block diagram for obtaining information about the connected devices on the client side.

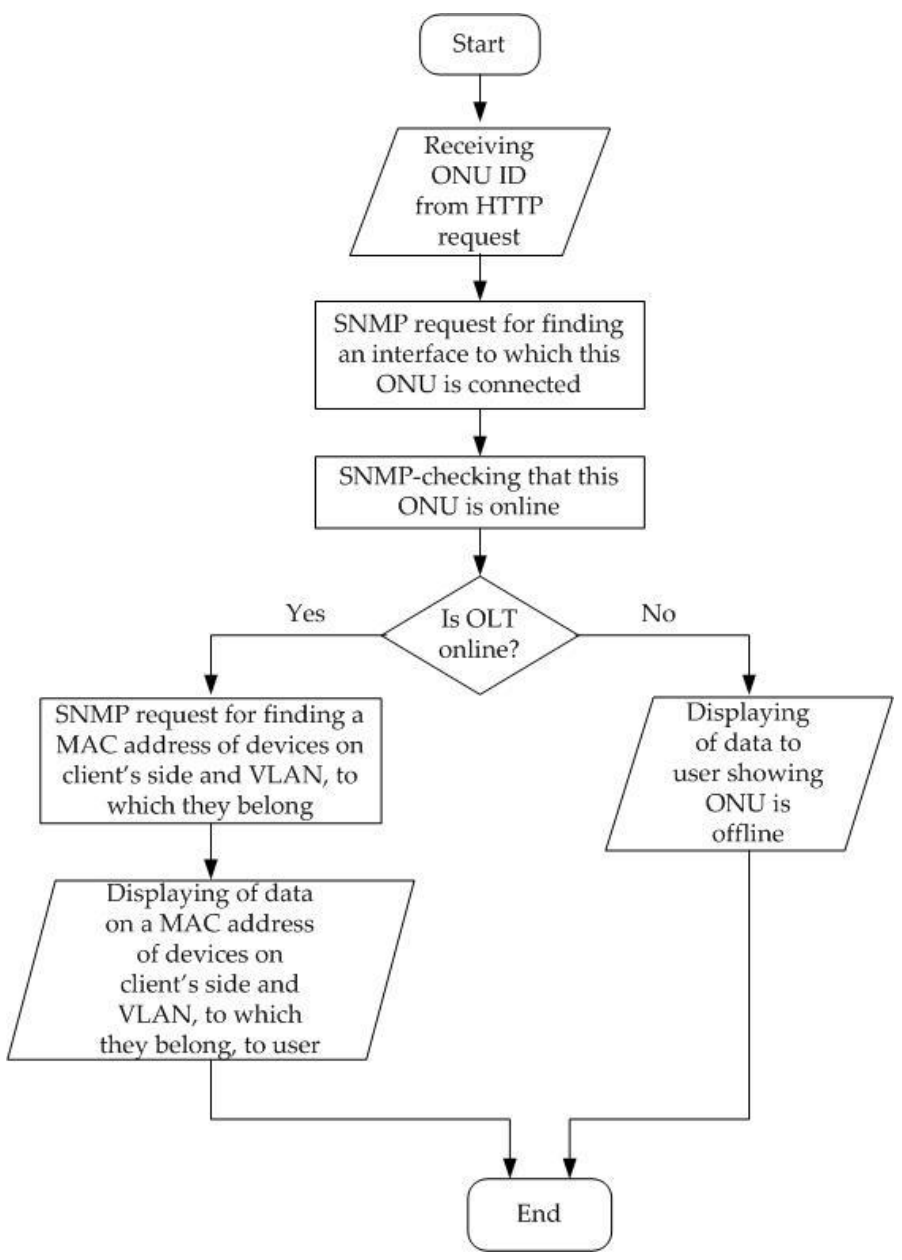

Fig. 4. The block diagram of the algorithm for displaying information about client devices in real time 
At the first stage of the algorithm, a unique ONU identifier must be obtained from the HTML request. After that, the database contains information about this ONU, and then there is an OLT, to which this ONU belongs.

The second stage aims to implement the following SNMP requests:

- a request to find the OLT interface, to which this ONU is connected;

- a request for a specific OLT interface and a check for the ONU being online.

If the ONU is offline, this information is displayed to the user. If the ONU is online, then an SNMP request is first made to find the MAC addresses of the devices on the client side and the VLAN, to which they belong, and then this data is displayed to the user.

\section{Creation of a database for solving the problems of monitoring a passive optical network}

To solve the problems of monitoring and controlling a passive optical network, a database has been created based on the proposed algorithms.

In the framework of system analysis, the minimum necessary set of objects of the subject area is identified. They are a User, an OLT, an ONU, and Signals History.

The database creation sequence is described using an OLT as the main object of the system. The OLT belongs to a User and can have many connected ONUs.

The OLT has the following relationships:

- "one-to-many" with the ONU entity (one OLT has many ONUs);

- "one-to-one" with the OLT (one ONU belongs to one OLT);

- "one-to-one" with the User (one OLT belongs to one User).

Some OLT entity attributes and their data types are shown in Table 1.

Table 1. Some OLT entity attributes and their data types

\begin{tabular}{|c|c|c|}
\hline Attribute & Data type & Description \\
\hline id & $\begin{array}{c}\text { UUID (Universally Unique } \\
\text { Identifier) }\end{array}$ & Unique identifier of the object \\
\hline user_id & String & $\begin{array}{c}\text { Unique identifier of the User to whom } \\
\text { the OLT belongs }\end{array}$ \\
\hline ip & String & IP Address of the OLT \\
\hline place & Text & Location of the OLT \\
\hline last_activity & Timestamp & OLT Last Online Date \\
\hline sfp_count & Integer & Sfp number \\
\hline
\end{tabular}

A fragment of the database on the example of the OLT entity as the main object of the system is shown in Fig. 5. 


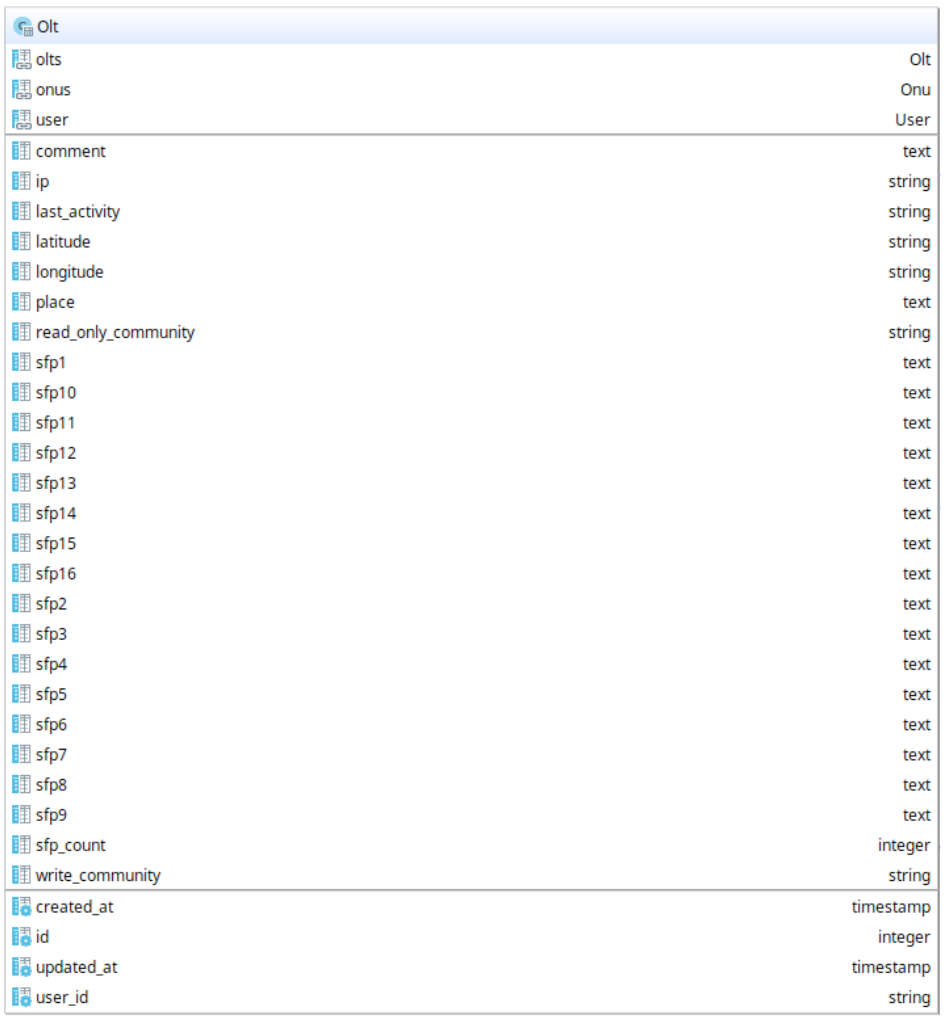

Fig. 5. A fragment of the database on the example of the OLT

An example of the operation code that corresponds to checking the input data, creating an OLT, recording to the database and finding information about the ONU is shown in Fig. 6.

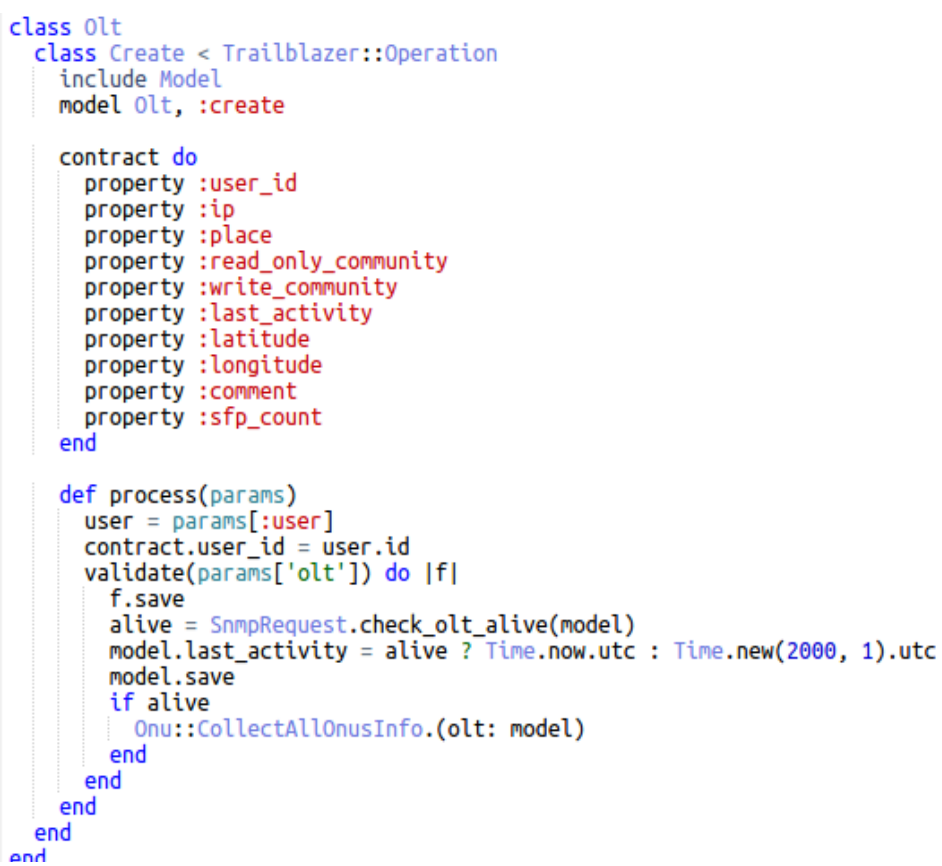

Fig. 6. Example of the operation code for creating an OLT 


\section{Conclusions}

Network management is an important function for maintaining a network in the operation state. Monitoring issues are resolved by providing the online customer service with reliable data on the current and predicted state of the network. It is shown that the operability of PON elements is provided due to timely monitoring using effective protocols and procedures. It was analyzed that to ensure the documentation of PON, algorithms are needed that allow processing and displaying OLT data structured according to the specifics of PON.

The algorithm has been developed for adding a new OLT and obtaining information about ONUs. It is considered that during the monitoring process, the system periodically checks important indicators of all available OLTs. The procedure for adding a new OLT and retrieving information about the ONU uses SNMP management.

It is shown that the use of the SNMP protocol for the development of the ONU state algorithm with the basic MIB-I and MIB-II standards for control information databases is focused on obtaining information on the operation of network elements and on collecting detailed statistics. The protocol allows unified management of equipment of different manufacturers working under different operating systems and at different levels of the OSI model.

The algorithm for displaying information about the ONU in real time has been developed. It is shown that in the process of monitoring the PON network, data obtained in real time, on-demand, have an important role. The presented algorithm displays information about the signal levels of the OLT-ONU and ONU-OLT as well as data on the distance of the OLT-ONU.

The algorithm for displaying information about client devices in real time has been developed. It is shown that information about client devices contains an ID with an HTML request, the MAC addresses of the devices on the client side, and the VLAN, to which they belong.

Based on the proposed algorithms, the creation of a database on the example of the OLT, which is the main object of the system, is considered. The minimum necessary set of objects of the subject area is allocated, an example of the operation code for creating an OLT is presented.

\section{References:}

1. Ubaidullaev R.R. Fiber-optic networks. Moscow: ECO-TRENDZ, 2000. 267 p.

2. Саенко И. Б., Скорик Ф. А., Котенко И. В. Мониторинг и прогнозирование состояния компьютерных сетей на основе применения гибридных нейронных сетей. ИЗВ. ВУЗОВ. ПРИБОРОСТРОЕНИЕ. 2016. Т. 59, №10. С. 795-800.

3. Нуреев И.И. Сенсорные пассивные оптические сети и кдючевые вопросы применения в них волоконных брэгговских решеток. Электронный научный журнал «Инженерный вестник Дона». №2. 2016. С. 22-53. 
4. Былина М.С., Глаголев С.Ф., Дюбов А.С., Хричков В.А. Модедирование специализированного оптического рефлектометра для контроля абонентских участков пассивных оптических сетей. XIV Международная научная конференция «Оптические технологии в телекоммуникациях». ОТТ-2016, 22-24 ноября. 2016. Самара, ПГУТИ. С. 118-119.

5. Аагутин И. А., Марамзин В.В. Расширенный алгоритм диагностики сетей на оборудовании Juniper. Электронный журнал «SCI-ARTICLE.RU». №11. 2014. C. 47-54.

6. Gaskevich E., Ubaidullaev R. PON - Broadband Multiservice Access Network. TeleMultiMedia. Vol. 2, No. 12. 2002. P. 29-32.

7. Olifer V. G., Olifer N.A. Computer networks. Principles, technologies, protocols. St. Petersburg: Peter, 2006. 992 p.

8. ITU-T X-208. Specification of Abstract Syntax Notation One (ASN.1). 1988. 74 p. URL: https://www.itu.int/rec/T-REC-X.208/en. 